\title{
ReCent Advances in CVD Synthetic Diamond Quality
}

\author{
Sally Eaton-Magaña and Ulrika F. S. D'Haenens-Johansson
}

Synthetic diamond growth was first documented in 1952 by William Eversole of the Union Carbide Corporation, but it took another two decades before GIA issued the first grading report for a laboratorymade diamond (Crowningshield, 1971). Virtually all single-crystal synthetic diamonds are made by two very different processes. High-pressure, high-temperature (HPHT) synthesis mimics some of the key conditions for natural diamond formation, with pressures of 5-6 GPa and temperatures of 1400$1600^{\circ} \mathrm{C}$ applied to a carbonaceous source material. The second method, chemical vapor deposition (CVD), involves growing synthetic diamond as thinfilm layers at moderate temperatures and low (i.e., below atmospheric) pressures. One of the main advantages of the CVD procedure over HPHT is the superior flexibility of synthetic diamond size and geometry produced. Furthermore, intentional doping with impurity elements can be controlled by the addition of gases containing those atoms.

Diamond, with its superlative physical properties, is of great interest for both scientific and technological reasons. CVD synthesis uses technology similar to that employed for producing silicon-based computer chips and electronics. In fact, many of the technological improvements in synthetic diamond quality are fueled by industrial applications, with commercial gem production a largely ancillary concern (Balmer et al., 2009).

Most current research efforts are focused on maximizing growth control and rates, improving purity, and understanding defect incorporation (e.g., Silva et al., 2008; Butler et al., 2009). The processes occurring in the gas phase and on the surface are complex and acutely sensitive to even minute changes to various parameters, such as surface orientation and smoothness, hydrocarbon-to-hydrogen ratio, substrate temperature, plasma density, and impurities present (e.g., Martineau et al., 2004; Silva et al., 2008).

As a result of this research effort, the quality of CVD products has advanced greatly over the last decade. Gem-quality CVD synthetic diamond (e.g., figures 1 and 2), once considered a "holy grail," is

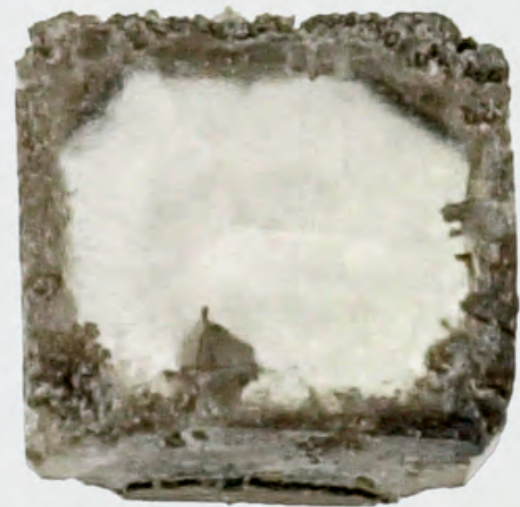

Figure 1. This 0.87 ct as-grown CVD synthetic diamond plate is near colorless and shows polycrystalline growth at the edges. Photo by Wuyi Wang.

now routinely produced thanks to several technical and experimental improvements.

\section{Improvements in Growth Chemistry}

In CVD synthesis, the feed gases are typically composed of hydrocarbons in a hydrogen-rich environment. The CVD reactor (figure 3) contains an energy source, such as microwave plasma, that splits the molecules into their constituent atoms or into molecular fragments (figure 4). For instance, methane $\left(\mathrm{CH}_{4}\right)$ dissociates into $\mathrm{CH}_{3}$ and $\mathrm{H}$. The carbon-based radicals diffuse down to the cooler substrate stage and react with the surface to create synthetic diamond and non-diamond carbon (Butler et al., 2009). The temperature is typically held at $700-1000^{\circ} \mathrm{C}$. A high concentration of hydrogen in the reactor drives the gas-phase and surface chemical reactions toward diamond. The precursor gas (e.g., $\mathrm{CH}_{4}$ ) is therefore heavily diluted in $\mathrm{H}_{2}$, with a typical mixing ratio of $0.1-8 \%$ by volume. 


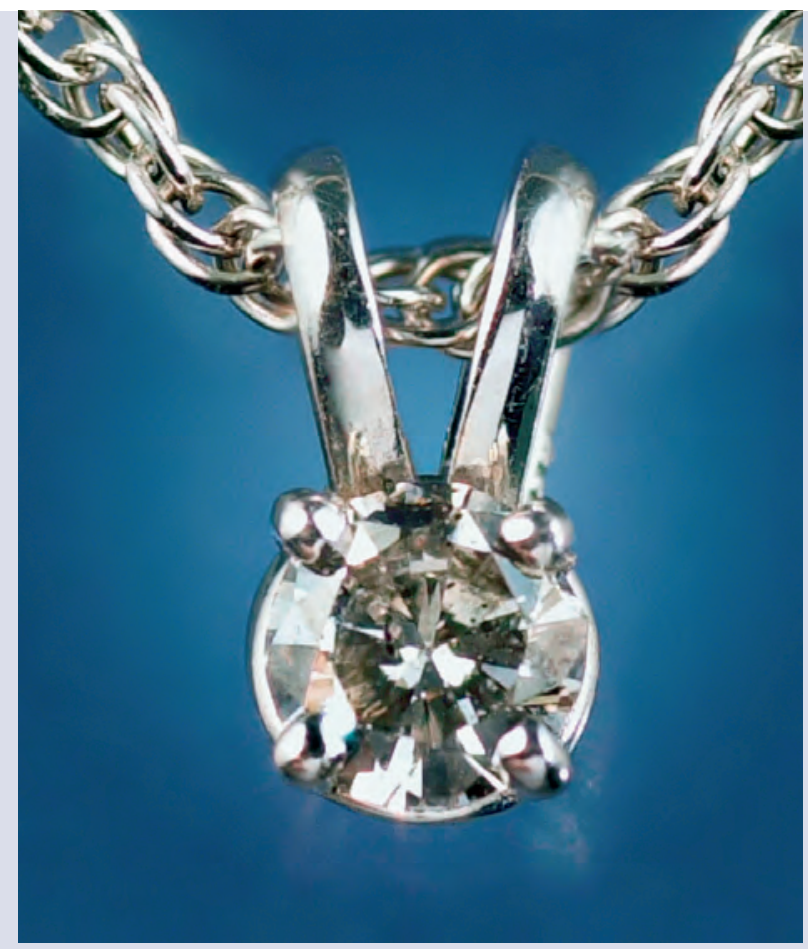

Figure 2. The $0.20 \mathrm{ct} C V D$ synthetic diamond in this pendant was manufactured by Apollo Diamond Inc. and has $\mathrm{SI}_{2}$ clarity and K color. Photo by Wuyi Wang.

All CVD techniques require a means to activate the gas-phase hydrogen and carbon-containing precursor molecules, and they are classified accordingly. Activation can occur using thermal methods (such as a hot filament), electric discharge (direct currents, radio frequencies, or microwaves), or a combustion flame. The vast majority of single-crystal CVD synthetic diamonds are grown using microwave-plasma CVD reactors.

Researchers have found that relatively minor changes to the growth parameters can yield large improvements. Such modifications include a redesigned substrate stage that helps maintain a stable microwave plasma and prevents plasma concentrations at the edges of the substrate, raising the growth rate 10-fold (Yan et al., 2002). A pressure increase from 60 to 200 torr (from 1/12 to 1/4 of atmospheric pressure) in the reactor improves the growth rate five-fold, while also reducing defects (Yan and Vohra, 1999). Researchers have also raised the microwave power to generate a high-density plasma. This allows uniform heating of the diamond substrate and raises the $\mathrm{H} / \mathrm{CH}_{3}$ concentration ratio within the reactor, which affects crystal size (Liang et al., 2009).

Intentional and unintentional addition of impurities can affect the growth rate, quality, and color of the synthetic diamond. A small amount of oxygen in the reactor gases can prevent the formation of cracks, thus maintaining single-crystal rather than polycrystalline growth (Tallaire et al., 2004; Friel et al., 2009). Additionally, minute quantities of nitrogen in the feed gases can enhance the growth rate eight-fold (Butler and Oleynik, 2008) while promoting crystallization on the $\{100\}$ face (Tallaire et al., 2006). However, nitrogen incorporated into the CVD synthetic diamond creates a yellowish or light brown color, necessitating further treatment (Martineau et al., 2004; Liang et al., 2009).

\section{Improvements in Substrate Material}

For single-crystal growth, the CVD film must be deposited on diamond-typically high-quality, HPHTgrown plates. Type Ib synthetic diamond traditionally served as the CVD substrate, but this resulted in lower-quality CVD material due to the high concentration of single-substitutional nitrogen in this

Figure 3. This schematic diagram shows some of the key components of a $2.45 \mathrm{GHz}$ ASTeX-microwave-plasma CVD reactor. Depending on the reactor size, the growth parameters, and the desired synthetic diamond quality, the growth area may vary in diameter between 2 and $20 \mathrm{~cm}$. Adapted from Martineau et al. (2004).

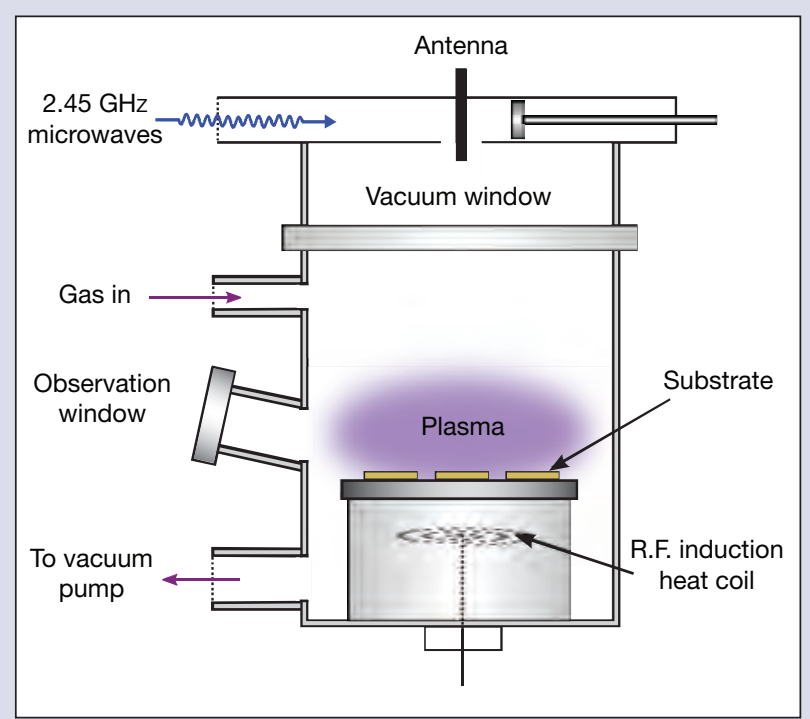




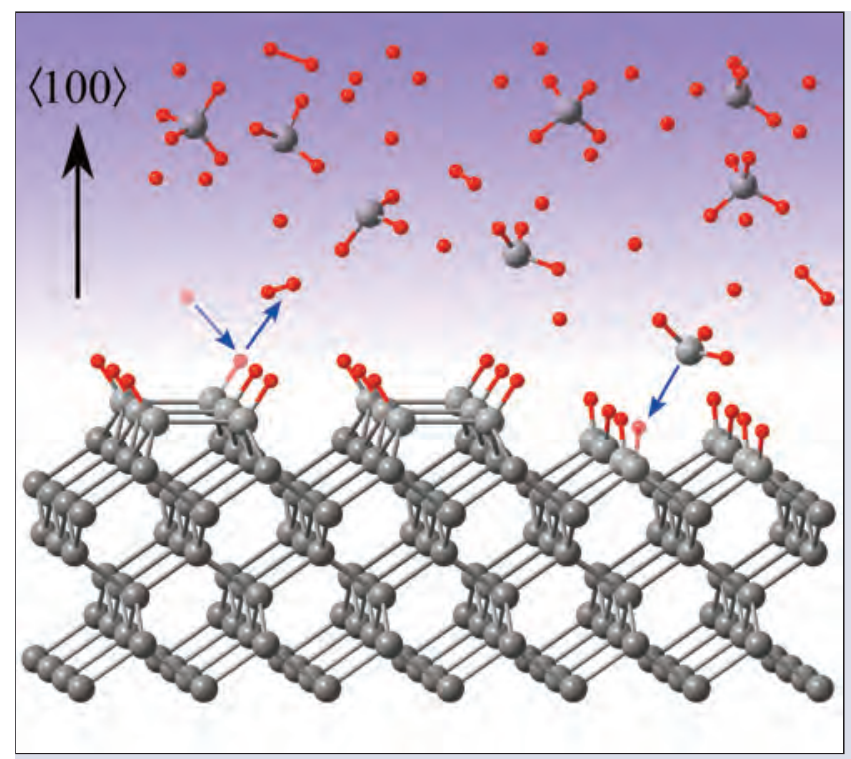

Figure 4. This drawing shows the simplified chemical reactions that occur during CVD synthetic diamond growth on a $\{100\}$ hydrogen-terminated surface showing $2 \times 1$ reconstruction (Butler et al., 2009). Carbon and hydrogen atoms are represented by gray and red spheres, respectively. The microwaves activate the gaseous reactants, resulting in a mixture of atomic hydrogen $(H)$, molecular hydrogen $\left(\mathrm{H}_{2}\right)$, and hydrocarbon species (e.g., $\mathrm{CH}_{4}$ and $\mathrm{CH}_{3}$ ). Two events are illustrated: an incident $H$ atom removing hydrogen from a $\mathrm{C}-\mathrm{H}$ bond on the surface, leaving an exposed carbon atom; and a $\mathrm{CH}_{3}$ molecule moving toward a separate exposed carbon site, where it may react to form the next synthetic diamond layer.

substrate. The lattice mismatch in the crystal structure between the type Ib substrate and the growing material (Lang et al., 1991) creates stress and additional opportunities for secondary nucleation (i.e., polycrystalline growth) and the generation of dislocations (Martineau et al., 2009). Type IIa HPHT-grown substrates are now available and offer several advantages over type Ib material, resulting in fewer defects in the CVD synthetic diamond (Twitchen et al., 2009).

Growth quality is influenced by the crystallographic orientation of the substrate growth plane, which should be oriented in the $\{100\}$ direction for best results. An angular deviation greater than $2^{\circ}$ from this direction leads to a significant decline in the quality of the CVD-grown synthetic diamond (Berdermann et al., 2004), making careful polishing and surface preparation of the substrate important for CVD synthesis.

\section{Improvements in Post-Growth Treatment}

As-grown brown CVD synthetics have three broad bands centered at $270 \mathrm{~nm}$ (due to substitutional nitrogen), $370 \mathrm{~nm}$, and $550 \mathrm{~nm}$ (Liang et al., 2009). Post-growth treatment rearranges the defects and impurities to improve optical and mechanical properties such as color, hardness, and fracture toughness. Both HPHT and careful low-pressure, high-temperature (LPHT) annealing can reduce the brown color in the as-grown CVD synthetic diamond, and each method has its own advantages (e.g., Meng et al., 2008). HPHT annealing is more commonly used, as the stabilizing pressure applied reduces the risk of graphitization. Although graphitization can be problematic with LPHT annealing, it can be conveniently performed within the CVD reactor after growth. Recently, researchers have succeeded in annealing single-crystal diamond at low pressures and at temperatures of $1400-2200^{\circ} \mathrm{C}$ within a hydrogen plasma, without significant graphitization (Meng et al., 2008; Liang et al., 2009). Depending on the treatment temperature chosen, there was a significant variation in annealing time, with the synthetic diamond held at the highest temperature for only 30 seconds. Notably, the CVD samples used by those authors were carefully chosen and prepared prior to treatment.

High-temperature annealing can decrease the 270 and $370 \mathrm{~nm}$ absorption bands, while the intensity of the band near $550 \mathrm{~nm}$ remains unchanged (Liang et al., 2009). On average, the color is improved by three grades.

\section{Future Potential}

With improvements in gas-phase chemistry and growth parameters, the greater availability of high-purity HPHT synthetic diamond as a starting material, and the effective application of post-growth treatments, the quality of CVD synthetic diamonds has improved considerably. Spectroscopic measurements verify that their purity is comparable to or even higher than that of typical type IIa natural diamond.

With all the recent progress in CVD synthesis, it continues to evolve as a major player on the engineering and gemological landscapes. We project that CVD synthetic diamond sizes will continue to 
increase and the available colors will expand beyond colorless, pink, and brown to include type IIb blue samples doped with boron. The use of CVD synthetic diamond as a coating material for natural diamond may become more widespread, though it

Drs. Eaton-Magaña (smagana@gia.edu) and D'Haenens-Johansson are research scientists at GIA, in Carlsbad and New York, respectively.

\section{References}

Balmer R.S., Brandon J.R., Clewes S.L., Dhillon H.K., Dodson J.M., Friel I., Inglis P.N., Madgwick T.D., Markham M.L., Mollart T.P., Perkins N., Scarsbrook G.A., Twitchen D.J., Whitehead A.J., Wilman J.J., Woollard S.M. (2009) Chemical vapour deposition synthetic diamond: Materials, technology and applications. Journal of Physics: Condensed Matter, Vol. 21, No. 36, article 364221 [23 pp.], http://dx.doi.org/10.1088/0953$8984 / 21 / 36 / 364221$.

Berdermann E., Ciobanu M., Hartmann W., Martemiyanov A., Moritz P., Pomorski M., Rebisz M., Voss B., Darmstadt G. (2004) Characterisation of single-crystal CVD-diamond detectors. http://gsi-heavy-ion-researchcenter.org/informationen/wti/library/scientificreport2004/PAPERS/INSTMETH35.pdf [date accessed: May 14, 2012].

Butler J.E., Oleynik I. (2008) A mechanism for crystal twinning in the growth of diamond by chemical vapour deposition. Philosophical Transactions of the Royal Society A: Mathematical Physical and Engineering Sciences, Vol. 366, pp. $295-$ 310.

Butler J.E., Mankelevich Y.A., Cheesman A., Ma J., Ashfold M.N.R. (2009) Understanding the chemical vapor deposition of diamond: Recent progress. Journal of Physics: Condensed Matter, Vol. 21, No. 36, article 364201 [20 pp.], http://dx.doi.org/ $10.1088 / 0953-8984 / 21 / 36 / 364201$.

Crowningshield R. (1971) General Electric's cuttable synthetic diamonds. $G \notin G$, Vol. 13, No. 10, pp. 302-314.

Friel I., Clewes S.L., Dhillon H.K., Perkins N., Twitchen D.J., Scarsbrook G.A. (2009) Control of surface and bulk crystalline quality in single crystal diamond grown by chemical vapour deposition. Diamond and Related Materials, Vol. 18, No. 5-8, pp. 808-815, http://dx.doi.org/10.1016/j.diamond.2009.01.013.

Koivula J.I., Kammerling R.C., Eds. (1991) Gem News: Bluish gray synthetic diamond thin films grown on faceted diamonds. $G \uplus G$, Vol. 27, No. 2, pp. 118-119.

Lang A.R., Moore M., Makepeace A.P.W., Wierzchowski W., Welbourn C.M. (1991) On the dilatation of synthetic type Ib diamond by substitutional nitrogen impurity. Philosophical Transactions: Physical Sciences and Engineering, Vol. 337, No. 1648, pp. 497-520, http://dx.doi.org/10.1098/rsta.1991.0135.

Liang Q., Yan C.-S., Meng Y., Lai J., Krasnicki S., Mao H.-K., Hemley R.J. (2009) Recent advances in high-growth rate single-crystal CVD diamond. Diamond and Related Materials, Vol. 18, No. 5-8, pp. 698-703, http://dx.doi.org/10.1016/ j.diamond.2008.12.002.

Martineau P.M., Lawson S.C., Taylor A.J., Quinn S.J., Evans D.J.F., has already occurred for research purposes (e.g., Koivula and Kammerling, 1991). Regardless of the advancements in CVD growth, well-equipped gem labs are still able to confidently identify these synthetic diamonds.

The authors thank Dr. James E. Butler for his suggestions on the manuscript.
Crowder M.J. (2004) Identification of synthetic diamond grown using chemical vapor deposition (CVD). Ge G, Vol. 40, No. 1, pp. 2-25, http://dx.doi.org/10.5741/GEMS.40.1.2.

Martineau P.M., Gaukroger M.P., Guy K.B., Lawson S.C., Twitchen D.J., Friel I., Hansen J.O., Summerton G.C., Addison T.P.G., Burns R. (2009) High crystalline quality single crystal CVD diamond. Journal of Physics: Condensed Matter, Vol. 21, No. 36, article 364205 [11 pp.], http://dx.doi.org/ 10.1088/0953-8984/21/36/364205.

Meng Y.-F., Yan C.-S., Lai J., Krasnicki S., Shu H., Yu T., Liang Q., Mao H.-K., Hemley R.J. (2008) Enhanced optical properties of chemical vapor deposited single crystal diamond by low-pressure/high-temperature annealing. Proceedings of the National Academy of Sciences, Vol. 105, No. 46, pp. 1762017625, http://dx.doi.org/10.1073/pnas.0808230105.

Silva F., Achard J., Bonnin X., Brinza O., Michau A., Secroun A., De Corte K., Felton S., Newton M., Gicquel A. (2008) Single crystal CVD diamond growth strategy by the use of a $3 \mathrm{D}$ geometrical model: Growth on (113) oriented substrates. Diamond and Related Materials, Vol. 17, No. 7-10, pp. 1067-1075, http://dx.doi.org/10.1016/i.diamond.2008.01.006.

Tallaire A., Achard J., Silva F., Sussmann R.S., Gicquel A., Rzepka E. (2004) Oxygen plasma pre-treatments for high quality homoepitaxial CVD diamond deposition. Physica Status Solidi (a), Vol. 201, No. 11, pp. 2419-2424, http://dx.doi.org/ 10.1002/pssa.200405164.

Tallaire A., Collins A.T., Charles D., Achard J., Sussmann R., Gicquel A., Newton M.E., Edmonds A.M., Cruddace R.J. (2006) Characterisation of high-quality thick single-crystal diamond grown by CVD with a low nitrogen addition. Diamond and Related Materials, Vol. 15, No. 10, pp. 1700-1707, http://dx.doi.org/10.1016/j.diamond.2006.02.005.

Twitchen D.J., Summerton G.C., Friel I., Hansen J.O., Guy K.B., Gaukroger M.P., Martineau P.M., Burns R.C., Lawson S.C., Addison T.P.G. (2009) High crystalline quality synthetic diamond. U.S. Patent No. 20090127506.

Yan C.S., Vohra Y.K. (1999) Multiple twinning and nitrogen defect center in chemical vapor deposited homoepitaxial diamond. Diamond and Related Materials, Vol. 8, No. 11, pp. 2022-2031, http://dx.doi.org/10.1016/S0925-9635(99)00148$\mathrm{X}$.

Yan C.S., Vohra Y.K., Mao, H., Hemley R.J. (2002) Very high growth rate chemical vapor deposition of single-crystal diamond. Proceedings of the National Academy of Sciences, Vol. 99, No. 20, pp. 12523-12525, http://dx.doi.org/10.1073/pnas.152464799. 